\title{
Sociodemographic and clinical factors associated with the decision time for seeking care in acute myocardial infarction ${ }^{1}$
}

\author{
Fernanda Carneiro Mussi ${ }^{2}$ \\ Mariana de Almeida Moraes Gibaut ${ }^{3}$ \\ Carla Almeida Damasceno ${ }^{4}$ \\ Andreia Santos Mendes ${ }^{3}$ \\ Armênio Costa Guimarães ${ }^{5}$ \\ Carlos Antonio de Souza Teles Santos ${ }^{6}$
}

Objective: this study aimed to analyze the interaction of gender in the association between decision time for seeking healthcare services and the sociodemographic and clinical variables. Method: this exploratory, cross-sectional study was performed with 100 individuals interviewed in hospitals in Salvador, Bahia. The chi-square test or Fisher's exact test and the robust linear regression model were used in the analysis. A statistical significance of $5 \%$ was adopted. Results: men and women presented long decision times. The decision time was less for smokers and those with constant and/or severe pain. There was an interaction between gender and smoking and between gender and pain radiating to the neck or jaw for the decision time outcome. Conclusion: decision times were long and were influenced by clinical and gender variables. The study provides support for nursing care practices focused on the specificity of these factors and of the genders aiming to reduce the decision time.

Descriptors: Myocardial Infarction; Gender Identity; Nursing Care.

\footnotetext{
${ }^{1}$ Paper extracted from masters thesis "Factors influencing the decision time for men and women with myocardial infarction to the demand for health services", presented to Universidade Federal da Bahia, Salvador, BA, Brazil. Supported by Fundação de Amparo à Pesquisa do Estado da Bahia (FAPESB) process \# APP0121/2009.

${ }^{2} \mathrm{PhD}$, Associate Professor, Escola de Enfermagem, Universidade Federal da Bahia, Salvador, BA, Brazil.

${ }^{3}$ Master's student, Escola de Enfermagem, Universidade Federal da Bahia, Salvador, BA, Brazil.

${ }^{4}$ MSc, Assistant Professor, IREP Sociedade de Ensino Superior, Salvador, BA, Brazil.

${ }^{5}$ PhD, Full Professor, Faculdade de Medicina, Universidade Federal da Bahia, Salvador, BA, Brazil. Full Professor, Escola Baiana de Medicina e Saúde Pública, Salvador, BA, Brazil.

${ }^{6} \mathrm{PhD}$, Adjunct Professor, Departamento de Ciências Exatas, Universidade Estadual de Feira de Santana, Feira de Santana, BA, Brazil. Researcher, Instituto de Saúde Coletiva, Universidade Federal da Bahia, Salvador, BA, Brazil.
}

Corresponding Author:

Fernanda Carneiro Mussi

Rua Professor Clementino Fraga, 220, Apto. 1901

Bairro: Ondina

CEP: 40170-050, Salvador, BA, Brasil

E-mail: femussi@uol.com.br
Copyright @ 2013 Revista Latino-Americana de Enfermagem This is an Open Access article distributed under the terms of the Creative Commons Attribution Non-Commercial License (CC BY-NC).

This license lets others distribute, remix, tweak, and build upon your work non-commercially, and although their new works must also acknowledge you and be non-commercial, they don't have to license their derivative works on the same terms. 


\section{Introduction}

Acute coronary syndromes are the leading worldwide cause of morbidity and mortality. Every year 7.1 million deaths occur due to coronary artery disease (CAD), with estimates of 11.1 million in $2020^{(1)}$. It is estimated that in Brazil, 300 to 400 thousand cases occur per year, and that death occurs in every 5 to 7 cases $^{(2)}$. In the state of Bahia, in 2010, 4137 deaths from acute myocardial infarction (AMI) were recorded, with 773 in the capital(3).

Half of all AMI deaths occur within the first hour after the onset of symptoms ${ }^{(4)}$, with survival depending on early treatment ${ }^{(1)}$. The time elapsed between the onset of symptoms and the coronary reperfusion is a determinant factor for the clinical course of the $\mathrm{AMI}^{(5)}$, as the effectiveness of coronary reperfusion therapies is time-dependent ${ }^{(5-6)}$. The delay in the implementation of these therapies remains an important obstacle to achieving their full benefit( ${ }^{(7)}$. Thus, one challenge is to identify the factors that contribute to the prehospital delay (time between the onset of symptoms and arrival at an emergency department) in patients with $\mathrm{AMI}^{(7)}$. Studies indicate the time taken to make the decision to seek a healthcare service (DT), i.e., the period between the onset of symptoms and the decision to seek a healthcare service, as the main component of this delay ${ }^{(5-6)}$. However, the studies are inconclusive regarding the reasons for this delay, especially between the genders ${ }^{(8)}$. It is important to consider that male and female social constructions may be involved in people's attitudes regarding their own health, influencing the course and the mortality of the disease. Therefore, gender may be a factor that differentiates behavior when faced with $\mathrm{AMI}^{(9)}$.

A number of factors have been highlighted concerning why individuals delay seeking healthcare, including socioeconomic (age, marital status, education, income, gender, etc.) and clinical (type of symptoms, duration and intensity of pain etc) conditions ${ }^{(5-6)}$. However, Brazilian literature regarding the influence of these factors on the DT is scarce. Knowledge about these factors will guide health practices to optimize the early search for care.

Therefore, the general aim of the study was: To analyze the interaction of gender on the association between the decision time and the sociodemographic and clinical variables. The specific aims were defined as: 1 . to estimate the decision time for men and women who suffered AMI; 2 . to verify the influence of sociodemographic and clinical variables on the decision time.

\section{Methods}

This exploratory, cross-sectional study was conducted in two reference hospitals for the treatment of AMI, located in Salvador, Bahia.

To calculate the sample size (n), 99/100,000 was taken as the parameter for the estimated prevalence of AMI in adults of Salvador-BA(10), and the sample calculation:

$$
n=\frac{N P(1-P)}{(N-1) D+P(1-P)} .
$$

Where, $D=\frac{B^{2}}{Z_{\alpha / 2}}$ and $\mathrm{P}(|\hat{P}-P| \leq B)=1-\alpha$.

$N$ - total population number assumed during the data collection period $=1,000 ; P$ - proportion within the study population $=0.099 ; n$ - sample size; $\alpha$-significance level; $(1-\alpha) 100 \%$ - degree of confidence; $B$ - estimated maximum error desired; $Z_{\alpha / 2}=1,96$; $1-\alpha=0,95 ; B=0.04$ or $4 \%(11)$.

According to the calculation, the sample size should be 99, opting for 100 individuals, using the inclusion criteria: medical diagnosis of AMI with or without ST-segment elevation recorded in medical records; hospitalization for at least 24 hours or a maximum time of 30 days post-AMI, to avoid recall bias; orientation in time and space, no medical restrictions for the interview and consent to take part in the study.

The selection of the subjects for the sample was performed with the identification of the individuals with a medical diagnosis of AMI in the registration book and confirmed in the patient records. Those that met the inclusion criteria and did not have any examinations and/or possible procedures for an hour were selected. The individuals were approached in the bed and informed of the aims of the investigation, identifying those interested in participating in the study through the signing of the Terms of Free Prior Informed Consent. The project was approved by the Ethics Committee, protocol 11/09, and complied with the ethical principles of Resolution 196/96(12).

The instrument developed for the data collection consisted of two parts with structured questions. Part I investigated sociodemographic data and Part II, data on cardiovascular risk factors (CVRF), clinical manifestations 
and type of AMI, interpretation of the symptoms and DT. The instrument was administered through interviews, conducted between April and November 2009.

The data were compiled in a database using the SPSS, version 17.0, program for Windows, and were analyzed as percentages and means. To analyze the association between the sociodemographic and clinical variables according to gender, the chi-square test was used, or Fisher's exact test with the occurrence of expected values below 5 , in $2 \times 2$ tables. In the bivariate and multivariate analyzes, using the robust linear regression model, the association between DT and the sociodemographic and clinical variables was verified, and the interaction term between the gender variable and the variables of interest was tested. For the analyzes, a logarithmic transformation was performed for the dependent variable DT to account for the asymmetry of the times. The significance level adopted was $5 \%$ for the tests $(p \leq 0.05)$.

\section{Results}

\section{Sociodemographic characterization}

The sample consisted of 100 individuals, with 29 women (W), aged between 41 and 87 years, and 71 men (M), aged between 27 and 80 years. The mean age for the $W$ group was 58.97 years \pm SD 12.10 and for the $M$ group 58.70 years \pm SD 11.08, with the age less than 60 years prevailing in the total sample and in both genders. Regarding the self-declared race/color, black was the most frequent in the total sample (71.0\%) and in both genders $(p=0.440)$. Considering the marital status, the majority were married or in a stable union $(75.0 \%)$, followed by separated $(9.0 \%)$, single $(9.0 \%)$, and widowed $(7.0 \%)$. It is noteworthy that, for both the $\mathrm{W}$ and $\mathrm{M}$ groups, the prevalent condition was being married or living with a partner $(p=0.099)$. Low education was predominant, with $69.0 \%$ of the sample having completed elementary education. This was also prevalent for the $M$ and $W$ groups $(p=0.908)$. Regarding the labor situation $67.0 \%$ were economically active, i.e. employed, self-employed or retired with activity, and $33.0 \%$ inactive due to being unemployed or retired with no activity. The gender and employment status variables were not associated. The predominant family income was up to three minimum wages for the total sample $(63.0 \%)$ and for the genders $(p=0.739)$. The prevalent number of dependents was up to three (58\%), which was also observed for both genders, without a significant association $(p=0.209)$. The majority of the sample lived in the company of a partner $(69.0 \%)$, with children
$(63.0 \%)$ and grandchildren $(23 \%)$, with a mean of two people per household. It was noted that those of the $M$ group more often lived with a partner compared to the $W$ group $(p=0.017)$, and that those of the $W$ group more often lived accompanied by granddaughters $(p=0.081)$. The majority of the participants were originally from the city of Salvador (70.0\%).

\section{Clinical characterization and the judgment of the pain as a symptom of AMI}

A family history of arterial hypertension (66\%) and CAD (50\%) were the most reported CVRFs. Regarding previous cardiovascular events, 52\% reported angina pectoris and $16 \%$ AMI. Acute myocardial infarction with ST-segment elevation prevailed, most frequent in the $M$ group $=51(71.8 \%)(p=0.025)$; (Table 1$)$.

The majority of the sample either did not know the nature of the symptoms (15\%) or had not interpreted them as being of cardiovascular origin ( $41 \%)$, in this case, the problem was assigned to the stomach $(24.0 \%)$, the spine $(9.0 \%)$, brain hemorrhage or arterial hypertension $(4.0 \%)$, stress/everyday problems $(3.0 \%)$, and effect of medication (1.0\%). Of the 44 participants who considered the symptoms to be of cardiovascular origin, $22.0 \%$ judged that they were suffering an AMI. A greater proportion of the $M$ group considered themselves victims of AMI or angina pectoris, although there was no significant association between gender and judgment of the nature of the symptoms. The symptoms were judged as sever by the majority of the sample $(64.0 \%)$, as well as by the $M$ and $W$ groups. The severity was justified due to severe pain and worsening of the symptoms or the association of the clinical condition with a cardiac problem.

In Table 2, it can be verified that the prevalent symptoms were chest pain $(81 \%)$, sweating $(67 \%)$, dyspnea (47\%), and pain radiating to the arms (43.0\%). For the $\mathrm{W}$ group the most frequent symptoms were dyspnea, pain radiating to the back and epigastrium, vomiting, syncope, and pain radiating to the jaw. Regarding the $M$ group, sweating, pain radiating to the arms and neck, nausea, dizziness, and palpitations predominated. The only associations verified were between gender and sweating, with a threshold significance $(p=0.054)$, more prevalent in the $M$ group, and between gender and jaw pain, with a significantly higher frequency for the $W$ group $(p=0.021)$.

Constant pain was more frequently reported than inconstant pain, for the total sample and the genders. One participant was unable to report this characteristic, having passed out at the onset of the symptoms. The 
type of pain most often mentioned was a squeezing pain $(45.0 \%)$, followed by burning $(36.0 \%)$, also predominant for the genders. A higher proportion of the $W$ group reported stabbing, heavy and tearing types of pain, and the $M$ group, burning and squeezing types of pain. There was an association between a heavy type of pain and gender, with a higher frequency for the $W$ group. Severe pain at the onset of symptoms was reported by $63.0 \%$ of the sample, also predominating for both groups. At the moment of the decision to seek care, 20 participants moved from the mild or moderate pain categories to severe.

Table 1 - Judgment of pain as a symptom of myocardial infarction and clinical characterization according to the sample and the genders. Salvador, BA, Brazil, 2010

\begin{tabular}{|c|c|c|c|c|c|c|c|}
\hline \multirow{2}{*}{ Variables } & \multicolumn{2}{|c|}{ Sample $(N=100)$} & \multicolumn{2}{|c|}{ Men $(n=71)$} & \multicolumn{2}{|c|}{ Women $(n=29)$} & \multirow{2}{*}{ p value* } \\
\hline & $\mathbf{n}$ & $\%$ & $\mathbf{n}$ & $\%$ & $\mathbf{n}$ & $\%$ & \\
\hline \multicolumn{8}{|l|}{ Report of cardiovascular risk factors } \\
\hline Arterial hypertension & 66 & 66.0 & 43 & 60.6 & 23 & 79.3 & 0.186 \\
\hline Family history of coronary artery disease & 50 & 50.0 & 34 & 47.9 & 16 & 55.2 & 0.696 \\
\hline Dyslipidemia & 31 & 31.0 & 19 & 26.8 & 12 & 41.4 & 0.239 \\
\hline Diabetes mellitus & 23 & 23.0 & 13 & 18.3 & 10 & 34.5 & 0.153 \\
\hline Smoker & 19 & 19.0 & 15 & 21.1 & 4 & 13.8 & 0.290 \\
\hline \multicolumn{8}{|l|}{ Coronary artery disease } \\
\hline Previous angina & 52 & 52.0 & 35 & 49.3 & 17 & 58.6 & 0.397 \\
\hline Previous acute myocardial infarction & 16 & 16.0 & 10 & 14.1 & 6 & 20.7 & 0.595 \\
\hline \multicolumn{8}{|l|}{ Type of acute myocardial infarction } \\
\hline With ST elevation & 65 & 65.0 & 51 & 71.8 & 14 & 48.3 & \multirow{2}{*}{0.025} \\
\hline Without ST elevation & 35 & 35.0 & 20 & 28.2 & 15 & 51.7 & \\
\hline \multicolumn{8}{|l|}{ Judgment of the symptoms } \\
\hline \multicolumn{8}{|l|}{ Regarding the nature } \\
\hline Associated with cardiac problem & 44 & 44.0 & 33 & 46.5 & 11 & 37.9 & 0,440 \\
\hline Did not associate with cardiac problem & 41 & 41.0 & 26 & 36.6 & 15 & 51.7 & 0,760 \\
\hline Did not know what it was & 15 & 15.0 & 12 & 16.9 & 3 & 10.3 & 0,309 \\
\hline \multicolumn{8}{|l|}{ Regarding the severity } \\
\hline Severe & 64 & 64.0 & 45 & 63.4 & 19 & 65.5 & \multirow{2}{*}{0,840} \\
\hline Not severe & 36 & 36.0 & 26 & 36.6 & 10 & 34.5 & \\
\hline
\end{tabular}

*The $\mathrm{P}$ values were obtained using the chi-square test or Fisher's exact test

Table 2 - Characteristics of the symptoms of acute myocardial infarction according to the sample and the genders. Salvador, BA, Brazil, 2010

\begin{tabular}{|c|c|c|c|c|c|c|c|}
\hline \multirow{2}{*}{ Variables } & \multicolumn{2}{|c|}{ Sample $(\mathrm{N}=100)$} & \multicolumn{2}{|c|}{ Men $(n=71)$} & \multicolumn{2}{|c|}{ Women $(n=29)$} & \multirow{2}{*}{$P$ value } \\
\hline & $\mathbf{N}$ & $\%$ & $\mathbf{N}$ & $\%$ & $\mathbf{n}$ & $\%$ & \\
\hline \multicolumn{8}{|c|}{ Acute myocardial infarction symptoms ${ }^{\dagger}$} \\
\hline Chest pain & 81 & 81.0 & 57 & 80.3 & 24 & 82.8 & 0.774 \\
\hline Sweating & 67 & 67.0 & 52 & 73.2 & 15 & 51.7 & 0.054 \\
\hline Dyspnea & 47 & 47.0 & 32 & 45.1 & 15 & 51.7 & 0.545 \\
\hline Pain radiating to the arms & 43 & 43.0 & 31 & 43.7 & 12 & 41.4 & 0.834 \\
\hline Pain radiating to the back & 35 & 35.0 & 23 & 32.4 & 12 & 41.4 & 0.393 \\
\hline Nausea & 32 & 32.0 & 23 & 32.4 & 9 & 31.0 & 0.895 \\
\hline Vomiting & 31 & 31.0 & 20 & 28.2 & 11 & 37.9 & 0.338 \\
\hline Dizziness & 20 & 20.0 & 17 & 23.9 & 3 & 10.3 & 0.123 \\
\hline Pain radiating to the neck & 17 & 17.0 & 13 & 18.3 & 4 & 13.8 & 0.711 \\
\hline Radiating epigastric pain & 18 & 18.0 & 11 & 15.5 & 7 & 24.1 & 0.307 \\
\hline Palpitation & 14 & 14.0 & 10 & 14.1 & 4 & 13.8 & 1.000 \\
\hline Syncope & 10 & 10.0 & 7 & 9.9 & 3 & 10.3 & 1.000 \\
\hline Headache & 6 & 6.0 & 3 & 4.2 & 3 & 10.3 & 0.352 \\
\hline Tremors & 2 & 2.0 & 2 & 2.8 & - & - & 1.000 \\
\hline Pain radiating to the jaw & 7 & 7.0 & 2 & 2.8 & 5 & 17.2 & 0.021 \\
\hline
\end{tabular}


Table 2 - (continuation)

\begin{tabular}{|c|c|c|c|c|c|c|c|}
\hline \multirow{2}{*}{ Variables } & \multicolumn{2}{|c|}{ Sample $(\mathrm{N}=100)$} & \multicolumn{2}{|c|}{ Men $(n=71)$} & \multicolumn{2}{|c|}{ Women (n=29) } & \multirow{2}{*}{ P value } \\
\hline & $\mathbf{N}$ & $\%$ & $\mathbf{N}$ & $\%$ & $\mathbf{n}$ & $\%$ & \\
\hline \multicolumn{8}{|l|}{ Characteristics of the pain } \\
\hline \multicolumn{8}{|l|}{ Constancy $(n=99)$} \\
\hline Constant & 66 & 66.0 & 49 & 69.0 & 17 & 58.6 & 0.319 \\
\hline Inconstant & 23 & 23.0 & 15 & 21.1 & 8 & 27.6 & 0.326 \\
\hline \multicolumn{8}{|l|}{ Type of pain } \\
\hline Squeezing & 45 & 45.0 & 33 & 46.5 & 12 & 41.4 & 0.642 \\
\hline Burning & 36 & 36.0 & 29 & 40.8 & 7 & 24.1 & 0.114 \\
\hline Cutting & 14 & 14.0 & 9 & 12.7 & 5 & 17.2 & 0.540 \\
\hline Stabbing & 13 & 13.0 & 7 & 9.9 & 6 & 20.7 & 0.144 \\
\hline Heavy & 6 & 6.0 & 2 & 2.8 & 4 & 13.8 & 0.057 \\
\hline \multicolumn{8}{|c|}{ Pain intensity at onset of symptoms } \\
\hline Mild & 4 & 4.0 & 3 & 4.2 & 1 & 3.4 & 0.578 \\
\hline Moderate & 33 & 33.0 & 26 & 36.6 & 7 & 24.1 & \\
\hline Severe & 63 & 63.0 & 42 & 59.2 & 21 & 72.4 & \\
\hline \multicolumn{8}{|c|}{ Pain intensity at the decision for care } \\
\hline Moderate & 17 & 17.0 & 10 & 14.1 & 7 & 24.1 & 0.359 \\
\hline Severe & 83 & 83.0 & 61 & 85.9 & 22 & 75.9 & \\
\hline
\end{tabular}

*The $\mathrm{p}$ values were obtained using the chi-square test or Fisher's exact test.

tEach individual reported more than one symptom

\section{Comparison of the DT according to sociodemographic factors, clinical factors and gender}

The geometric mean (GM) and median of the DT were, respectively, $1.1 \mathrm{~h}$ and $1.0 \mathrm{~h}$. For the $\mathrm{W}$ group, the GM of the DT was $1.4 \mathrm{~h}$ and the median $1.5 \mathrm{~h}$, and for the $M$ group, the GM was $0.9 \mathrm{~h}$ and the median $1.0 \mathrm{~h}$. The $\mathrm{W}$ group presented longer mean decision times than the $M$ group, however, the difference was not statistically significant.

There was no significant association between DT and the sociodemographic variables, and there was no interaction between gender and these variables for the DT outcome.

Among the CVRFs there was a significant association between DT and smoking, in which smokers presented shorter DTs $(p=0.052)$. There was also an interaction between gender and smoking for the DT outcome $(p=0.017)$, where the smokers of the $W$ group presented longer DT $(2.4 \mathrm{~h})$ than the smokers of the $M$ group (0.3h) (Table 3 ).

There was no significant association between DT and the interpretation of the symptoms as cardiovascular problems, however, the people who had judged the problems to be cardiovascular presented shorter DTs. Those who considered the symptoms severe also presented shorter DTs $(p=0.007)$. There was no interaction between gender and assigning severity to the symptoms or interpretation of the nature of the symptoms as cardiac for the DT outcome (Table 3 ).

Table 3 - Cardiovascular risk factors, interpretation of the nature of the symptoms and of their severity associated with the decision time and the gender. Salvador, BA, Brazil, 2010

\begin{tabular}{|c|c|c|c|c|c|}
\hline \multirow[b]{2}{*}{ Variables } & \multicolumn{5}{|c|}{ Geometric Mean, in hours, of the decision time } \\
\hline & $\begin{array}{l}\text { Sample } \\
(\mathrm{N}=100)\end{array}$ & P value* $^{*}$ & $\begin{array}{c}\text { Men } \\
(n=71)\end{array}$ & $\begin{array}{c}\text { Women } \\
(n=29)\end{array}$ & $P_{\text {value }}^{\dagger}$ \\
\hline \multicolumn{6}{|l|}{ Report of cardiovascular risk factors } \\
\hline \multicolumn{6}{|l|}{ Arterial hypertension } \\
\hline Yes (66) & 1.1 & \multirow{2}{*}{0.990} & 1.0 & 1.2 & \multirow{2}{*}{0.278} \\
\hline No (34) & 1.1 & & 0.9 & 2.9 & \\
\hline \multicolumn{6}{|l|}{ Smoker } \\
\hline Yes (18) & 0.5 & 0.052 & 0.3 & 2.4 & 0.017 \\
\hline No (82) & 1.3 & & 1.3 & 1.3 & \\
\hline \multicolumn{6}{|l|}{ Diabetes mellitus } \\
\hline Yes (23) & 1.0 & 0.405 & 1.1 & 0.9 & 0.510 \\
\hline No $(77)$ & 1.1 & & 0.9 & 1.8 & (continue \\
\hline
\end{tabular}


Table 3 - (continuation)

\begin{tabular}{|c|c|c|c|c|c|}
\hline \multirow[b]{2}{*}{ Variables } & \multicolumn{5}{|c|}{ Geometric Mean, in hours, of the decision time } \\
\hline & $\begin{array}{l}\text { Sample } \\
(N=100)\end{array}$ & P value* & $\begin{array}{c}\text { Men } \\
(n=71)\end{array}$ & $\begin{array}{c}\text { Women } \\
(n=29)\end{array}$ & P value \\
\hline \multicolumn{6}{|l|}{ Judgment of the symptoms } \\
\hline Associated with cardiac problem (44) & 0,8 & 0.289 & 0.7 & 1.2 & 0.764 \\
\hline Not associated with cardiac problem (56) & 1,3 & & 1.2 & 1.5 & \\
\hline \multicolumn{6}{|l|}{ Severity of the symptoms } \\
\hline Severe (64) & 0,8 & 0.007 & 0.6 & 1.1 & 0.470 \\
\hline Not severe (36) & 2,0 & & 1.9 & 2.1 & \\
\hline
\end{tabular}

*Shows the difference between the categories of the specific variables

tShows the heterogeneity between men and women (the interaction). All p values were obtained using the robust linear regression model

Regarding the type of symptoms, there was a significant association between pain radiating to the neck or pain radiating to the jaw and DT $(p=0.015$ and $p=0.018$, respectively), where the subjects who experienced these types of pain took longer to decide to seek a healthcare service than those who did not feel them. A statistically significant interaction was also verified between gender and pain radiating to the neck, as well as gender and pain radiating to the jaw, and the DT outcome. Among the pain characteristics, regardless of gender, it was found that constant pain was a significant factor in the reduction of the DT compared to intermittent pain, while mild pain at onset of symptoms was a significant factor in the increase of the DT compared to moderate intensity pain (Table 4).

Table 4 - Clinical manifestations of acute myocardial infarction associated with the decision time and gender. Salvador, BA, Brazil, 2010

\begin{tabular}{|c|c|c|c|c|c|}
\hline \multirow[b]{2}{*}{ Variables } & \multicolumn{5}{|c|}{ Geometric Mean of the decision time, in hours } \\
\hline & $\begin{array}{l}\text { Sample } \\
(\mathrm{N}=100)\end{array}$ & P value* & $\begin{array}{c}\text { Men } \\
(n=71)\end{array}$ & Women $(n=29)$ & $\mathbf{P}$ value ${ }^{\dagger}$ \\
\hline \multicolumn{6}{|l|}{ Type of symptoms } \\
\hline \multicolumn{6}{|l|}{ Chest pain } \\
\hline Yes (81) & 1.0 & 0.848 & 0.9 & 1.5 & 0.339 \\
\hline No (19) & 1.2 & & 1.3 & 0.9 & \\
\hline \multicolumn{6}{|l|}{ Sweating } \\
\hline Yes (66) & 0.9 & 0.286 & 0.8 & 1.5 & 0.366 \\
\hline No (34) & 1.4 & & 1.5 & 1.3 & \\
\hline \multicolumn{6}{|l|}{ Dyspnea } \\
\hline Yes (47) & 1.0 & 0.580 & 1.0 & 0.9 & 0.179 \\
\hline No (53) & 1.2 & & 0.9 & 2.4 & \\
\hline \multicolumn{6}{|l|}{ Nausea } \\
\hline Yes (32) & 1.0 & 0.715 & 0.9 & 1.1 & 0.774 \\
\hline No (68) & 1.1 & & 1.0 & 1.6 & \\
\hline \multicolumn{6}{|l|}{ Dizziness } \\
\hline Yes (20) & 1.0 & 0.929 & 1.1 & 0.8 & 0.600 \\
\hline No $(80)$ & 1.1 & & 0.9 & 1.5 & \\
\hline \multicolumn{6}{|l|}{ Pain radiating to neck } \\
\hline Yes (17) & 2.4 & 0.015 & 3.3 & 0.9 & 0.011 \\
\hline No (83) & 0.9 & & 0.7 & 1.5 & \\
\hline \multicolumn{6}{|l|}{ Epigastric pain } \\
\hline Yes (18) & 0.9 & 0.538 & 0.9 & 0.8 & 0.407 \\
\hline No (82) & 1.1 & & 0.9 & 1.7 & \\
\hline \multicolumn{6}{|l|}{ Palpitations } \\
\hline Yes (14) & 1.0 & 0.964 & 1.5 & 0.4 & 0.154 \\
\hline No (86) & 1.1 & & 0.9 & 1.7 & \\
\hline \multicolumn{6}{|l|}{ Pain radiating to jaw } \\
\hline Yes (7) & 4.2 & 0.018 & 26.6 & 2.0 & $<0.001$ \\
\hline No (93) & 1.0 & & 0.9 & 1.3 & (continue \\
\hline
\end{tabular}


Table 4 - (continuation)

\begin{tabular}{|c|c|c|c|c|c|}
\hline \multirow[b]{2}{*}{ Variables } & \multicolumn{5}{|c|}{ Geometric Mean of the decision time, in hours } \\
\hline & $\begin{array}{l}\text { Sample } \\
(\mathrm{N}=100)\end{array}$ & P value* $^{*}$ & $\begin{array}{c}\text { Men } \\
(n=71)\end{array}$ & Women $(n=29)$ & P value $^{\dagger}$ \\
\hline \multicolumn{6}{|l|}{ Characteristics of the pain } \\
\hline \multicolumn{6}{|l|}{ Constancy } \\
\hline Constant (66) & 0.7 & 0.000 & 0.6 & 1.1 & 0.244 \\
\hline Inconstant (34) & 2.7 & & 3.0 & 2.2 & \\
\hline \multicolumn{6}{|l|}{ Type of pain } \\
\hline \multicolumn{6}{|l|}{ Squeezing } \\
\hline Yes (45) & 1.4 & 0.215 & 1.1 & 2.4 & 0.471 \\
\hline No (55) & 0.9 & & 0.8 & 1.0 & \\
\hline \multicolumn{6}{|l|}{ Burning } \\
\hline Yes (36) & 0.7 & 0.141 & 0.7 & 0.9 & 0.945 \\
\hline No (64) & 1.3 & & 1.2 & 1.6 & \\
\hline \multicolumn{6}{|l|}{ Tearing } \\
\hline Yes (14) & 1.7 & 0.348 & 2.3 & 0.9 & 0.127 \\
\hline No (86) & 1.0 & & 0.8 & 1.6 & \\
\hline \multicolumn{6}{|l|}{ Stabbing } \\
\hline Yes (13) & 2.1 & 0.145 & 1.7 & 2.7 & 0.897 \\
\hline No (87) & 1.0 & & 0.9 & 1.2 & \\
\hline \multicolumn{6}{|l|}{ Heavy } \\
\hline Yes (6) & 0.7 & 0.499 & 0.4 & 1.0 & 0.653 \\
\hline No (94) & 1.1 & & 1.0 & 1.5 & \\
\hline \multicolumn{6}{|l|}{ Pain intensity at onset of symptoms } \\
\hline Mild (4) & 6.6 & 0.000 & 4.5 & 20.0 & 0.351 \\
\hline Moderate (35) & 2.1 & & 1.7 & 3.9 & \\
\hline Severe (61) & 0.6 & & 0.6 & 0.8 & \\
\hline
\end{tabular}

*Shows the difference between the categories of the specific variables

tShows the heterogeneity between men and women (the interaction). All the p values were obtained using the robust linear regression mode

\section{Discussion}

In this study, men with AMI were predominant, corresponding to findings in the literature(5). The women developed AMI earlier, considering the age limits of 55 years for men and 65 years for women, taken as the cutoff points for premature myocardial infarction in relation to gender ${ }^{(13)}$. The sample presented homogeneous sociodemographic characteristics, as it was composed of Brazilian Nation Health Service (SUS) users, primarily originating from the city of Salvador and its metropolitan area, who declared themselves mostly of black race/color and lived in conditions of social inequality evidenced by low education and family income. These findings confirm the descriptions in the literature of these characteristics as potentiators for the risk of cardiovascular disease ${ }^{(14-15)}$.

Both the $\mathrm{M}$ group and $\mathrm{W}$ group were slow to decide to seek care, however, the women presented a higher DT (1.4h vs. 0.9h), which exposed them to an increased risk of mortality, considering that approximately $50 \%$ of people with AMI die within the first hour of the development of a cardiovascular event ${ }^{(2)}$. It must be considered that after the making the decision they still spent time getting to a health service prior to the diagnosis and treatment.

A higher proportion of the $\mathrm{M}$ group presented AMI with ST-segment elevation compared with the W group. Given the benefits of chemical or mechanical reperfusion, in this type of AMI, actions that encourage the reduction of DT are indispensable in order to optimize the benefits of these therapies, which vary in an inverse ratio to the time of their application(16).

Although it is believed that the recognition of cardiovascular symptoms demands critical skills that may be affected in the group with less education, and that low income may hinder access to health services, in this study variations in income and education were not associated with higher DTs or with gender. Authors have also found independence between these variables ${ }^{(5-6,16)}$. Because the sample was composed of SUS users, income may not have been an obstacle to seeking care, considering that it is free.

Despite the prevalence of typical clinical manifestations of AMI, both for the total sample as well as for the gender groups, the vast majority (84\%) 
reported that it was the first episode of AMI and were, therefore, unfamiliar with the symptoms, perhaps hindering the adoption of appropriate actions in relation to the cardiovascular event. This fact, associated with low socioeconomic status, may explain why only $44 \%$ of them associated the pain with a cardiac problem or did not know what it meant. Although not statistically significant, it should be noted that the interpretation of the symptoms as a cardiac problem was responsible for shorter DT, as already stated by other authors ${ }^{(17)}$. Although there was no interaction with gender, it was observed that those of the $M$ group that judged the symptoms as a cardiac problem had lower DTs. The judgment of the symptoms as a cardiac problem was more common for the group of men, possibly because of beliefs that AMI is a disorder pertaining to this gender or the fact that women do not judge themselves to be susceptible to cardiovascular events ${ }^{(13)}$.

Considering that $64 \%$ attributed severity to the symptoms and $56 \%$ did not associated them with AMI or did not know about their origin, it is possible to assume that the recognition of the potential severity of the clinical condition occurred in the course of the cardiovascular event, i.e., when the participants began to realize the symptoms could not be improved using personal resources or could no longer tolerate the pain. The interpretation of the severity of the AMI was determinant for shorter DT, revealing the importance of the conscientization of the community in general regarding seeking care early faced with the AMI, even in the absence of symptoms judged intolerable.

Regarding the DT and its relationship with the sociodemographic factors, the literature indicates that women and people over 70 years of age present a combination of less typical symptoms of $\mathrm{AMI}^{(17-19)}$ and therefore may delay the decision to seek care. However, in this study, there was no significant association between DT, age and gender, with it being noted that the majority of the women and men suffered the infarction prior to 60 years of age and with typical symptoms of AMI.

In this study, the CVRFs identified agree with those described in the literature ${ }^{(13,20-21)}$ as causal factors for CAD and prevalent in groups in situations of social inequality. The lack of association between the CVRFs reported and gender was also observed by other authors(13). There was no significant association between DT and diabetes mellitus type II, although the literature suggests that diabetics delay seeking care ${ }^{(22)}$. The justifications for the prehospital delay in diabetics are not very clear, but were associated with altered perception of the pain due to neuropathy, or the presentation of symptoms nonspecific for $\mathrm{AMI}^{(22)}$.

The smokers presented lower DT (0.5h vs. 1.3h; $\mathrm{p}=0.052)$, indicating that smokers may perceive a greater risk of becoming ill. This perception seems to be predominantly related to the male gender, responsible for the significant DT reduction in this group. Therefore, women smokers especially need to receive special attention from the programs aimed at reducing prehospital delay faced with AMI.

The symptoms of AMI described by the participants were characteristic and corresponded to those found in the literature(20-21). Regarding the particular type of pain, increased DT was significantly influenced by pain radiating to the neck and jaw, with males primarily responsible. Concerning the intensity of the pain, longer DTs were also found when it was classified as mild, in both genders. Conversely, severe and/or constant pain was associated with a significant decrease in the DT, with no difference between the genders, suggesting that sever pain can lead people to seek care faster due to their intolerance, while atypical symptoms can make them underestimate the seriousness ${ }^{(9,23)}$. It is likely that the radiation of pain out of the precordial region and/or its weak intensity would put into question its interpretation as a cardiac problem, allowing it to be associated with musculoskeletal problems, particularly in men.

This study highlights the importance of the need for basic information about the CVRFs, typical and atypical symptoms of AMI, and the risk of the delay in seeking care. The results clarified particularities of each gender that caused longer or shorter DTs faced with the AMI, contributing to the identification of risk groups. The identification of the clinical and sociodemographic factors implicated in the delay in seeking a healthcare service, guide health professionals in educational activities with the patients, family members and the community aimed at reducing the $\mathrm{DT}^{(16)}$.

\section{Conclusions}

The study made contributions regarding the sociodemographic and clinical factors that affect the DT faced with the symptoms of AMI and their relationships with the genders. Long DTs were observed for the genders, with the women displaying longer times, however, this difference was not statistically significant. Clinical factors were associated with the DT, with shorter DTs highlighted for smokers, and those with constant 
and sever pain. The study also allowed the conclusion that there was an interaction between gender and smoking, as well as between gender and pain radiating to the neck or jaw, for the DT outcome.

These findings guide healthcare actions aimed at seeking care early. Considering the health education component of nursing care practices, it is the nurse who should propose and evaluate effective interventions, based on specificities of the genders, which stimulate and valorize early treatment faced with AMI. The delay in the decision to seek care indicates the need for guidance and training to help individuals to recognize the symptoms of AMI and to valorize the immediate pursuit of an emergency service. The sample size can be highlighted as a possible limitation of the study. It is possible to suggest the hypothesis that with larger samples other significant associations could have been found.

It should also be considered that the present study focused on the interaction between the clinical and sociodemographic variables and gender regarding the DT outcome, therefore, other variables, such as the cultural and environmental factors, need to be evaluated in further studies.

\section{References}

1. Timerman S, Marques FBR, Pispico A, Ramires JAF. Tratamento pré-hospitalar da síndrome isquêmica aguda com supradesnivelamento do segmento ST: já temos suficiente. evidência para implantar rotina? Rev Soc Cardiol Estado São Paulo 2004;14(6):868-83.

2. Sociedade Brasileira de Cardiologia. III Diretriz sobre tratamento do infarto agudo do miocárdio. Arq Bras Cardiol. 2004;83(supl. 4):9-86.

3. Ministério da Saúde (BR). Indicadores de Saúde. Datasus. [Internet]. [acesso 13 mai 2012]. Disponível em: http://www2.datasus.gov.br/DATASUS/index.php? area $=02$.

4. Sociedade Brasileira de Cardiologia. IV Diretriz sobre o tratamento do Infarto Agudo do Miocárdio com supradesnível do segmento ST. Arq Bras Cardiol. 2009;93(supl 2):179-264.

5. Gärtner C, Walz L, Bauernschmitt E, Ladwig KH. The causes of prehospital delay in myocardial infarction. Dtsch Arztebl Int. 2008;105(15):286-91.

6. Horne R, James D, Petrie K, Weinman J, Vincent R. Patients' interpretation of symptoms as a cause of delay in reaching hospital during acute myocardial infarction. Heart. 2000;83:388-93.
7. Mussi FC, Ferreira SL, Menezes AA. Experiences of women in face of pain from acute myocardial infarction. Rev Esc Enferm USP. 2006;40(2):170-8.

8. Devon HA, Zerwic JJ. Symptoms of acute coronary syndormes: are there gender differences? A review of the literature. Heart Lung. 2002;31(4):235-45.

09. Mussi FC, Pereira A. Pain tolerance during myocardium infarction. Acta Paul Enferm. 2010;23(1):80-7.

10. Lessa I. Epidemiologia das doenças cerebrovasculares no Brasil. Rev Soc Cardiol Estado São Paulo. 1999;9(4):509-18.

11. Kish L. Survey Sampling. New York: Witley; 1965. p. 59. 12. Ministério da Saúde (BR). Conselho Nacional de Saúde. Resolução 196, de 10 de Outubro de 1996. Sobre a pesquisa envolvendo seres humanos. [Internet] Brasília. [acesso 10 set 2010] Disponível em: http:// conselho.saude.gov.br/comissao/conep/resolucao.html.

13. Conti RAS, Solimene MC, Luz PL, Benjá AM, Neto PAL, Ramires JAF. Comparison Between Young Males and Females with Acute Myocardial Infarction. Arq Bras Cardiol. 2002;79(5):510-7.

14. Ishitani LH, Franco GC, Perpétuo IH, França E. Socioeconomic inequalities and premature mortality due to cardiovascular diseases in Brazil. Rev Saúde Pública. 2006;40:684-91.

15. Gama GGG, Mussi FC, Pires CGS, Guimarães AC. Crenças e comportamentos de pessoas com doença arterial coronária. Ciênc Saúde Coletiva. 2012;17(12):3371-83.

16. Franco B, Rabelo ER, Goldemeyer S, Souza EN. Patients with acute myocardial infarction and interfering factors when seeking emergency care: implications for health education. Rev. Latino-Am. Enfermagem. 2008;16(3):414-8.

17. Moser DK, Mckinley S, Dracup K, Chung ML. Gender differences in reasons patients delay in seeking treatment for acute myocardial infarction synptoms. Patient Educ Counsel. 2005;56:45-54.

18. Isaksson RM, Holmgrem L, Lundblad D, Brulin C, Eliasson M. Time trends in symptoms and prehospital delay time in women vs. men with myocardial infarction over a 15-year period. The Northern Sweden MONICA Study. Eur J Cardiovasc Nurs. 2008;7:152-8.

19.Ting $\mathrm{HH}$, Bradley $\mathrm{EH}$, Wang $\mathrm{Y}$, Lichtman $\mathrm{JH}$, Nallamothu BK, Sullivan MD, et al. Patient Education to Reduce Prehospital Delay Time in Acute Coronary Syndrome. Arch Intern Med. 2008;168(9):959- 68.

20. Evangelista PA, Barreto SM, Guerra HL. Hospital admission and hospital death associated to ischemic heart diseases at the National Health System (SUS). Arq Bras Cardiol. 2008;90(2):130-8. 
21. Santos FLMM, Araújo TL. Having an infarction: the meanings of the disease from the patient's perspective. Rev. Latino-Am. Enfermagem. 2003;11(6):742-8.

22. Goldberg RJ, Steg PG, Sadiq I, Granger CB, Jackson EA, Budaj A, et al. Extent of, and factors associated with, delay to hospital presentation in patients with acute coronary disease (the GRACE registry). Am J Cardiol. 2002;89(7):791-6.

23. Ying $W$, Ying $Z$, Yu-Qiu L, Bao-Li $H$, Cong-Xin $H$. Factors associated with the extent of care-seeking delay for patients with acute myocardial infarction in Beijing. CMJ. 2004:117(12):1772-7. 